\title{
Reflections on mental health advocacy across differing ecological levels
}

\author{
Nancy J. Thompson, PhD, MPH, ${ }^{1}$ Robin E. McGee, MPH, ${ }^{2}$ Leslie C. Munoz, MPH, MLitt, ${ }^{3}$ and Elizabeth R. Walker, PhD, MPH ${ }^{4}$ \\ ${ }^{1}$ Associate Professor, Department of Behavioral Sciences and Health Education, Rollins School of Public Health of Emory University, Atlanta, \\ GA; ${ }^{2}$ Doctoral Student, Department of Behavioral Sciences and Health Education, Rollins School of Public Health of Emory University, \\ Atlanta, GA; ${ }^{3}$ Doctoral Student, Department of Behavioral Sciences and Health Education, Rollins School of Public Health of Emory \\ University, Atlanta, GA; and ${ }^{4}$ Postdoctoral Fellow, Department of Health Policy and Management, Rollins School of Public Health of Emory \\ University, Atlanta, GA
}

\begin{abstract}
Background: According to the World Health Organization, mental health advocacy is comprised of a range of actions designed to change aspects of attitudes and structures that impede the achievement of positive mental health in populations.

Methods: According to the World Health Organization, mental health advocacy is comprised of a range of actions designed to change aspects of attitudes and structures that impede the achievement of positive mental health in populations.

Results: We have proposed interventions and advocacy effort for each ecological level. Project UPLIFT, a distance-delivered intervention for mental health is presented as an example of an effort that can affect several levels of the social ecology.

Conclusions: Advocacy and interventions that make an effort to encompass the levels of the social-ecological model may contribute to greater progress in improving mental health outcomes.
\end{abstract}

Key Words: Mental Health, Advocacy, Social Ecology, Individual Level, Relationship Level, Community Level, Societal Level

\section{INTRODUCTION}

Mental health is a significant public health concern worldwide. Mental disorders contribute substantially to the burden of disease, since a mental or behavioral disorder will affect about one in five people during his or her lifetime (Kessler et al., 2009). In the United States, over the course of a year, more than one in five people have a mental disorder meeting diagnostic criteria. As a result, about onefourth of the total disability in the United States results from mental disorders (Kessler, Chiu, Demler, \& Walter, 2005).

In the state of Georgia, almost five percent of residents live with serious mental illness. About one in four of these is a child (U. S. Public Health Service, 2000). Still, only about 21 percent of those in the state with serious mental illness receive services through Georgia's public mental health system (Aron et al., 2009). In 2006, Georgia expended only 1.7 percent of all state spending, about $\$ 61$ per capita, on mental health agency services (National Association of State Mental Health Program Directors Research Institute, Inc., 2006). Most care for mental illness occurs at the community level. Nationally, about 70 percent of mental health agency spending is devoted to community mental health services; in Georgia, the figure is 52 percent (National Association of State Mental Health Program Directors Research Institute, Inc., 2006).

gapha www.jgpha.com
Due to scarcity of mental health resources and housing alternatives for those with serious mental illness, family members and others who are close to them often assume supportive functions and provide care for these people (Lefley, 2009). This, too, has a cost. In addition to providing medical support, those informally caring for people with mental disorders also have to manage the stigma associated with many mental illnesses (American Psychological Association, n. d.). Moreover, these persons are more likely than other caregivers to have to make work accommodations and to report a decline in their own health as a result of their role (The National Alliance for Caregiving and AARP, 2009).

Perhaps the greatest cost, however, is to the people with mental illness themselves. In the United States, unemployment levels are 75-90 percent among those with mental illness, contributing to their financial cost (Waghorn \& Lloyd, 2005). The social and emotional costs are substantial, as well. According to 2007 data from the Centers for Disease Control and Prevention (2013), only one-fourth of adults with symptoms of mental illness believed that people are caring and sympathetic to persons with mental illness. Furthermore, a study across 12 countries found that 14 of 18 mental disorders were associated with a lower likelihood of ever marrying, and all 18 were associated with a higher likelihood of divorce (Breslau et al., 2011). This is a reflection of the fact that chronic mental illness often contributes to poor connections 
with others and unsatisfying relationships (Drew, 1991), in addition to internalized stigma and low self-worth (Drapalski et al., 2013).

Social-ecological models (Figure 1) evolved in an effort to understand the dynamic interplay of influences between people and their environments, bridging the gap between behavioral and social theories (McLaren \& Hawe, 2005). As described, mental health requires attention across varying levels from the individual, to the caregiver, to the community, to the larger society, including Georgia and other states, countries, and the global community. Guided by this model (see Figure 1), we have explored some of the areas that require our attention and advocacy as we work to improve mental health in Georgia.

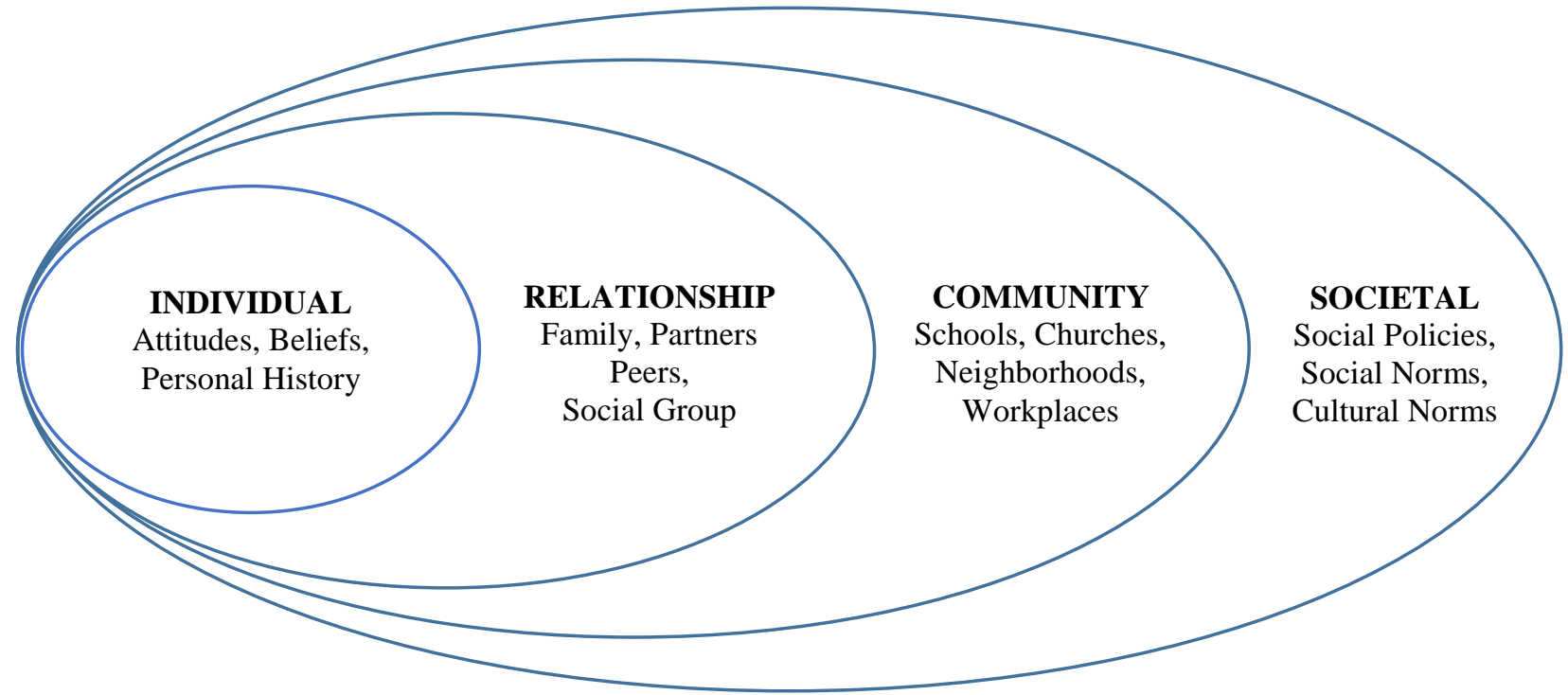

Figure 1. Social-ecological model

\section{Mental Health Advocacy and the Individual}

Individuals with mental illness face a variety of problems on a day-to-day basis. Among these are feelings of isolation based upon atypical experiences and the associated social stigma; confusion about whether and when to rely on one's own perceptions; difficulty determining whose perceptions to trust; and the physical sensations and physical health outcomes that can result from stress, depression, anxiety, and other disorders. These factors can also reduce the ability of the individual to access care, which, when inaccessible, leaves few avenues for relief. This section covers the issues of internalized stigma, self-compassion, co-morbidity with other chronic disease, and access to care, and proposes interventions for which we can advocate to address these issues and improve the lives of people with mental illness.

\section{Internalized stigma and self-compassion}

When a person with mental illness encounters stereotypes and other negative assumptions about mental illness, emotionally or cognitively takes them in, and starts to believe them about her- or himself, the result is called "internalized stigma" (Drapalski et al., 2013). Internalization of stigma leads to isolation and withdrawal, as well as to a lowered self-concept. These, in turn, lead to higher levels of psychiatric symptoms (Drapalski et al., 2013). Stigma and discrimination are often encountered by those with mental illness. As noted in the Introduction, a national survey found that only one of four adults with mental illness symptoms believed that people are caring and sympathetic toward those with mental illness (Centers for Disease Control and Prevention, 2013). In light of the fact that more than one in three people with mental illness manifest internalized stigma, it appears that even fewer may be caring and sympathetic toward themselves, (Drapalski et al., 2013; West, Yanos, Smith, Roe, \& Lysaker, 2011). Thus, while we work to reduce mental health stigma and discrimination at a social level, it is also necessary to advocate for means of protecting the individual from the adverse effects of these conditions. One such mean is self-compassion.

Self-compassion involves extending kindness toward ourselves; seeing our experiences as part of human experience and having a balanced perspective on our suffering, rather than thinking it is all that we are (Neff, 2003). Through learning self-compassion, we learn not to avoid distressing feelings but to be aware of them with kindness, allowing us to regulate our emotions (Neff, 2003). Self-compassion is a stronger predictor of coping than selfesteem or optimism (Sbarra, Smith, \& Mehl, 2012). Thus, self-compassion correlates positively with mental health and negatively with a variety of mental disorders (Neff, Rude, \& 
Kirkpatrick, 2007). This suggests that we should advocate for opportunities for people with mental illness to learn the skill of self-compassion as protection against the ecological forces that might otherwise engender self-criticism. Mindfulness-based interventions increase self-compassion (e.g., Shapiro, Brown, \& Biegel, 2007).

\section{Chronic disease comorbidity and access to care}

Another problem area for those with mental illness is in the intersection of physical and mental health. In some cases, mental illness precedes physical illness; those with mental illness have a higher risk of chronic disease (De Hert et al., 2011). In other cases, physical illness may contribute to the onset of anxiety, depression, or other mental disorders. In either case, having both conditions together is more debilitating than either condition alone (Kessler, Ormel, Demmler, \& Stang, 2003). Nonetheless, there are disparities in delivery of physical health care for those with mental illness (De Hert et al., 2011). Moreover, those with mental illness have difficulty with chronic disease selfmanagement, including medication adherence (e.g., Gehi, Haas, Pipkin, \& Whooley, 2005; Lin et al., 2004).

An approach to this problem is to address the barriers to intervention and monitoring of physical health among people with mental illness, i.e., to start by identifying and engaging those with mental illness. Another approach is to provide mental health skills, among other self-management skills, to people with chronic disease, i.e., to start by identifying and engaging those with chronic physical disease. The latter has advantages in that physical disease is typically less stigmatized than mental disease.

Project UPLIFT is a program designed to do the latter (Thompson et al., 2014). This program teaches cognitivebehavioral and mindfulness skills to improve the mental health of people with chronic disease, regardless of which condition came first. These skills are effective in treating a variety of mental disorders, including depression, anxiety, post-traumatic stress disorder, and schizophrenia (Bryant, 2011; Hofmann, Sawyer, Witt, \& Oh, 2010; Jones, Hacker, Cormac, Meaden, \& Irving, 2012). Project UPLIFT, groupdelivered by telephone and the Web, provides access for those with physical health problems that can make in-person attendance problematic. Distance delivery can also bypass the problem of stigma associated with attending a mental health center. Thus far, Project UPLIFT has been effective for both treatment and prevention of depression and anxiety (Thompson et al., 2014; Thompson et al., 2010). Studies of other mental health disorders are under development, both for individuals with chronic disease and their caregivers.

Much research has demonstrated that home-based telehealth is cost-effective (Rojas \& Gagnon, 2008), and home-based tele-mental health is effective (Dellifraine \& Dansky, 2008). Advocating for a home-based tele-mental health program such as Project UPLIFT includes working on policies to facilitate distance delivery by licensed professionals and gaining reimbursement by third-party payers to make these programs broadly available to those with mental illness and chronic disease.

\section{Mental Health Advocacy and the Relationship}

Caring for someone with a chronic mental and/or physical health condition can be taxing for the caregiver. The National Alliance for Caregiving and AARP (2009) estimates that 65.7 million Americans are informal caregivers. This number is likely to rise as the American population ages and the prevalence of chronic disease increases. Caregiving has become more recognized as a public health issue due to the large number of caregivers and the impact of caregiving on the health of the caregivers. This section outlines the spectrum of support that caregivers provide and examines the mental health implications associated with the caregiving burden. Also discussed are interventions for supporting caregivers, which could potentially improve their mental health.

\section{Spectrum of Support}

Caregivers provide a range of support to their loved ones, including assistance with disease management and daily tasks, emotional support, tangible aid, and services. These activities can take a few hours a week or most of each day, depending on the severity of the loved one's condition. Support from caregivers is associated with better health outcomes for the care recipient (Franks et al., 2006; Rosland, Heisler, \& Piette, 2012), particularly when the support is encouraging, focuses on enhancing patient autonomy, and fosters family cohesion (Rosland et al., 2012).

Support for disease management includes reminders and help for taking medications, going to doctor appointments, and contributing to making medical decisions. It can also include supporting healthy eating, exercise, and stress relief (Gallant, Spitze, \& Prohaska, 2007; Rosland et al., 2012; Walker et al., 2014). Depending on the mobility and capacities of the loved one, caregivers may need to help with one or more tasks of daily living, such as bathing or meal preparation (National Alliance for Caregiving \& AARP, 2009). Instrumental support, including housing and financial support, is often needed from caregivers. Emotional support, which includes encouragement and expressions of empathy, trust, and caring, is another facet of the support provided by caregivers (Heaney \& Israel, 2008).

In regard to support for disease management, there is a spectrum in terms of who leads the management efforts (Walker et al., 2014). Loved ones with less debilitating conditions may lead their own disease management efforts but may still need emotional and instrumental support. Joint management most often occurs in the case of spouses, who work together to manage the loved one's conditions. Finally, caregivers may take on the main role of disease management in cases where the loved one is incapacitated, which can result in a heavy caregiver burden. At each stage of this continuum, the caregiver and recipient must balance the desire for independence with the need for care. The loved ones may want, but be unable, to do things on their own. Conversely, the caregivers may feel that their lives are constricted by care demands (Walker et al, 2014). Within the relationship, negotiations must occur to reach a workable balance for both individuals. 


\section{Caregiver Burden}

The caregiving burden is multidimensional and includes direct care of a loved one and disruption in the family's life and activities (Sales, 2003). Caregiving responsibilities negatively impact the caregivers' quality of life, as well as physical and mental health (Rees, O'Boyle, \& MacDonagh, 2001; Smerglia, Miller, Sotnak, \& Geiss, 2007). A metaanalysis by Pinquart and Sorensen (2003) demonstrated that individuals caring for elderly adults are more likely to experience depression, stress, and poor general health compared to non-caregivers. Activity restriction is a mediator between the caregiving burden and depressive symptoms, indicating that caregivers' mental health is negatively affected by the constraints that providing care places on their lives (Nieborer et al., 1998).

Caregivers, particularly parents, of people with mental illness face the challenge of providing extended caregiving. Mental illnesses often emerge in adolescence or young adulthood and thus require long-term support (Aschbrenner, Greenberg, Allen, \& Seltzer, 2010). Additionally, family members and caregivers can experience stigma associated with their loved one's mental illness. Stigma by association includes social exclusion, blame for the individual's conditions, and not being taken seriously, and is associated with emotional distress in the caregiver (Sanden, Stutterheim, Pryor, Kok, \& Bos, 2014).

\section{Advocacy and interventions at the relationship level}

To provide effective care and to cope with the difficulties of caregiving and stigma by association, supports can benefit caregivers. In a qualitative study of caregivers who experienced depression, three main interventions that participants felt would be especially beneficial were support groups, respite care, and financial aid (Ramsay, Walker, Ramsay, Compton, \& Thompson, 2010). Support groups allow caregivers to connect with each other and share stories. However, caregivers often have difficulty in finding time to attend such groups. Respite care, where a loved one can be watched for a limited time, gives the caregivers an opportunity for rest and personal time. The downsides to respite programs are that they can be far away, especially for caregivers living in rural areas, and are not always affordable. Finally, financial assistance provides caregivers some relief from financial strain, especially when the caregiver cannot work due to the needs of their loved one. Financial assistance often is based upon complex eligibility criteria and application processes that can be difficult to navigate (Ramsay et al., 2010). Advocating for policies that provide easier access to these services could ease the burden on caregivers and lessen the strain on both caregivers and their loved ones. Once again, this would involve advocacy for distance-delivered programs.

\section{Mental Health Advocacy and the Community}

Although most mental health services are provided at the community level, there are limitations to mental health advocacy at this level that create barriers to effective implementation of interventions. These factors include, but are not limited to, trust, community norms, needs unique to diverse populations, licensing laws, and the availability of emergency and safety services. This section outlines ways in which each of these factors influences mental health services at the community level. The section concludes by describing how being mindful of these factors can increase community-level access to mental health services.

\section{Trust and norms}

In delivering mental health interventions, trust is a factor in ensuring the success and sustainability of a program. Since trust is relational and built over time, we are often dependent on those individuals in communities who are already trusted as sources of support and collaboration when advocating for enhanced access to community-level resources. In Project UPLIFT, described above, the model is to use a person from the targeted population as a cofacilitator, but these individuals must be carefully selected because their presence in the group influences the participation of others in their community, either positively or negatively. The previously cited study by Ramsay and colleagues (2010) highlights issues surrounding trust associated with mental health care at the community level. Caregivers in this study stressed the need to have someone they know to help them cope with the stress of caregiving because they were concerned with issues of confidentiality (Ramsay et al., 2010), revealing a tension between wanting to get help and feeling uncomfortable accessing it. Other caregivers raised concerns over the use of computer technology, which indicates that these technological methods may not always provide the best way to make interventions accessible to hard-to-reach populations. To enhance access to mental health services in communities, we should recognize that who and what method of interaction is trusted may look different within and across communities. To reach people and provide them with resources in a way that is meaningful to them, we need to advocate for recognizing the norms of each community and for incorporating these norms into our programs. Creating resources that are consistent with community norms helps make them more accessible.

\section{Considering diverse populations}

Within communities, there may be subpopulations that face additional barriers to accessing mental health resources. The diversity within a community must, therefore, be considered when promoting these resources. Cultural differences within a community can pose additional barriers to allowing diverse populations to access mental health resources (Morris, Popper, Rodwell, Brodine, \& Brouwer, 2009). The communication or manifestation of symptoms may vary across cultural groups, thus creating a complex dynamic that can influence quality of care when the culture of the patient differs from that of the medical provider (Office of the Surgeon General, Center for Mental Health Services, \& NIMH, 2001). Regarding symptoms, a review of primary care and population-based studies found that depression and anxiety disorders are associated with the presentation of somatic symptoms that cannot be explained by the methods of the healthcare practitioner (Kroenke, 2003). Furthermore, access to a support system and coping style also affect an individual's interface with the healthcare system.

Refugees and other immigrant groups are community subpopulations for consideration, especially in Georgia. As 
of May 2014, Georgia ranked eighth in receiving the most refugee arrivals in the United States (Bureau of Population, Refugees, and Migration, 2015). Refugee populations often experience high levels of psychological distress as a result of displacement-related stressors (Pernice \& Brook, 1996; Miller \& Rasco, 2004; Gorst-Unsworth \& Goldenberg, 1998). Depression rates range from 5-21\% among different refugee groups (Martens, 2007; Ao et al., 2012). A recent study involving Bhutanese refugees resettled in the United States found that their annual age-adjusted suicide rate was 24.4 per 100,000; approximately double that of U.S. residents (12.4 per 100,000) (Ao et al., 2012). Furthermore, influenced by differences in social norms regarding social support for people with mental illness, many Bhutanese refugees use withdrawal and self-harming coping mechanisms to deal with stress, rather than seek out mental health services (Chase, 2012).

Despite these statistics and concerns, there is a lack of community-based mental health interventions for refugee populations. Moreover, there are circumstances faced by refugees that pose additional challenges to accessing mental health services. Language barriers limit an individual's ability to navigate their new environment and communicate with people outside of their community, particularly to identify and seek out specialized medical services. Since many adults are reliant on their children as translators, having appropriate translators can help these individuals in the resettlement process. Beyond the language barrier, the significance of a health program may be lost if a person does not share the same view on disease etiology. Translating materials and helping these individuals understand when, where, and why a program is taking place is essential. Many adult refugees are caregivers for both children and elderly family members and cannot be expected to access mental health services if they do not have support systems in place that allow them to prioritize their health needs. Transportation is also a widely recognized barrier for refugees because they often lack the financial means to buy a car and are therefore reliant on public transportation systems. Such reliance requires that we be mindful of the timing of programs and where they take place so they are accessible. To advocate for the mental health of diverse populations, we should recognize when barriers such as these limit the reach of community-level resources.

Professional licensing and emergency and safety services Telehealth is a promising approach to delivering mental health services to underserved areas and geographically isolated populations. It allows health care providers to employ technologies, such as telephone and video conferencing, to deliver health-related services directly to patients in places where no providers are available or when it is difficult to reach patients in an effective manner. However, telehealth is not only limited to reaching patients who have access to a qualified medical facility (ATA, 2013), the practice places the burden on mental health professionals to become licensed in each state in which they have patients for whom they are providing care. For example, Georgia law states that psychologists in other states providing services to patients in Georgia must be licensed to practice in Georgia (Representation of Services, 2004). Thus, when distance delivery takes place across state lines, there are barriers for both the patient and the psychologist. Tele-mental health also poses challenges when practiced community-to-community within a state, particularly concerning the capacity to provide emergency services to patients in need. To ensure the safety of their patients, mental health professionals practicing distance delivery services must become familiar with or advocate for emergency service referrals where their patients are located.

\section{Advocacy and interventions at the community level}

As noted, to advocate for enhanced access to mental health services at the community level, we need to consider the subpopulations within communities who face additional barriers to accessing mental health services. Language translation, culturally sensitive materials, and ease of access are relevant aspects of intervention. Engaging trusted people from the community to assist in developing intervention materials that reflect appropriate language and cultural norms is an essential step in this process. Intervention materials that reflect appropriate language and cultural norms can then be delivered throughout the community, and, with distance delivery, throughout the state of Georgia. If groups do not have access to the technology required for distance delivery, however, equipment and training will need to be provided or alternative methods explored. Advocating for access to inexpensive equipment such as throw-away telephones and training in the use of the equipment could enhance access to community-level mental health services and ease the burden on groups that are disproportionately affected by mental illness and who face barriers to seeking treatment services.

\section{Mental Health Advocacy and the Society}

In 2010, Healthy People 2020 added a goal to "create social and physical environments that promote good health for all" (U.S. Department of Health \& Human Services (HHS), 2014 , p. 3). For achieving this goal, the objectives focus on key areas and underlying factors, including economic stability, social and community context, and health and health care (HHS, 2013). In this section, we discuss some underlying factors that influence mental health outcomes at the societal level, including the distribution of wealth, stigma and discrimination, and access to health care. We also discuss how cost data may assist in advocating for interventions that may contribute to addressing these societal-level influences.

\section{Income inequality}

In the United States, income inequality has worsened over the last few decades. In 2013, the top five percent of household income accounted for $22.2 \%$ of all income, whereas in 1980, the top five percent accounted for only 16.5\% (U.S. Census Bureau, 2014). Locally, a 2014 analysis of income inequality in 50 cities found that Atlanta was the most unequal city (Berube \& Holmes, 2015). This is relevant because income inequality is related to worse mental health outcomes (Pickett \& Wilkinson, 2015).

The relationship between income inequality and mental health exists at various levels of influence. For instance, 
Burns and colleagues (2014) found that a one-point increase in income inequality at the country level corresponded with a two-point increase in the incidence of schizophrenia. In another longitudinal study at the state level, depression was related to income inequality (Pabayo, Karachi, \& Gilman, 2014). However, this relationship was statistically significant only for females, not males (Pabayo et al., 2014). The authors hypothesized that a reason for the gender difference is that income inequality may contribute to the erosion of social networks and social cohesion, and women may be more likely to be influenced by these factors (Pabayo et al., 2014). With evidence supporting the relationship between income inequality and mental health outcomes at various geographic levels and for various mental illnesses, addressing income inequality may prove helpful in reducing the burden of mental health problems.

\section{Stigma and discrimination}

Stigma and discrimination also influence mental health outcomes at the societal level. Individuals who have such experience have worse mental health outcomes (e.g., Bostwick et al., 2014; Soto, Dawson-Andoh, BeLue, 2011). People may be subject to stigma and discrimination based on age, gender, disability, race/ethnicity, sexual orientation, and mental health status, among others. Those who experience more than one type of discrimination are more likely to report mental health problems (Bostwick et al., 2014; Soto et al., 2011). For example, when lesbian, gay, and bisexual adults experience discrimination based on sexual orientation and race/ethnicity, they are more likely to report a mental health disorder, and the likelihood increases with the more types of discrimination they experience (Bostwick et al., 2014). Similarly, as determined in a study examining the relationship between discrimination and generalized anxiety disorder among African Americans, Afro Caribbeans, and non-Hispanic Whites, those who experienced more discrimination were more likely to report generalized anxiety disorder (Soto et al., 2011). For racebased discrimination, only African Americans reported greater levels of anxiety (Soto et al., 2011).

Stigma and discrimination related to mental health status also have effects on mental health outcomes and on disparities in health care, education, and employment outcomes (Hatzenbuehler, Phelan, \& Link, 2013). Delay in accessing mental health care due to stigma and discrimination (Clement et al., 2014) or experiences of stigma and discrimination within the health care system may reduce the quality of care that individuals receive (Thornicroft, Rose, \& Kassam, 2007).

\section{Health care access}

Limited access to mental health care coverage is a potential consequence of stigma and discrimination. Historically, within the health care system, mental health services have not been covered equally with physical health services. This unequal access may contribute to inadequate provision of services. A study of mothers with depression found that $38 \%$ did not receive any treatment; only 35\% received adequate treatment (Witt et al., 2011). Even those with access to treatment did not receive adequate services. While the 2008 Mental Health Parity and Addiction Equity Act and the 2010 Patient Protection and Affordable Care Act (ACA) provide legislation to improve the provision of mental health care (Beronio, Glied, \& Frank, 2014), monitoring and evaluating the extent to which insurance companies are complying with the new rules of parity is needed (Langheim, Shim, \& Druss, 2015).

Gaining insurance coverage benefits mental health outcomes. Oregon implemented a health plan that expanded access to health care for low-income, uninsured individuals (Baicker et al., 2013). Those who received insurance coverage reported lower rates of depression than those who did not (Baicker et al., 2013). Providing access to insurance may reduce stress and the financial strain associated with accessing health care services, which could influence mental health outcomes (Baicker et al., 2013; Langheim et al., 2015).

\section{Advocacy and interventions at the societal level}

To make substantial changes in the societal-level factors that influence mental health, changes to policy and programs that address areas of influence are needed. Data that demonstrate the cost effectiveness and benefits of programs may help convince decision-makers about the value of these programs. Some examples of programs that have collected and provided this type of information are described below.

Income Inequality: Vinokur and colleagues (1991) developed an effective intervention to assist individuals who had lost their jobs. Those who participated in an employment support program that focused on reducing poor mental health outcomes had a quicker return to work and had higher wage earnings, thus reducing their income disparity. The authors estimated that this would benefit each participant by more than $\$ 45,000$ over a working lifetime, (Vinokur et al., 1991).

Stigma and Discrimination: In the United Kingdom, results of a national campaign to reduce stigma related to mental illnesses suggested that the benefits of the intervention outweighed the costs (Evans-Lacko et al., 2013). The authors estimated that more people with depression have the potential to access services and gain employment, providing a positive economic benefit in relation to campaign costs.

Health care Access: Programs like Project UPLIFT (Thompson et al., 2014) have the potential to demonstrate value due to the distance- and group-delivery format. Future innovations in health care delivery, as well as increased access to care, may demonstrate cost-effectiveness and benefits. Evaluating the cost-effectiveness and benefits of these programs could provide support for their dissemination.

Demonstrating the potential value of interventions, in addition to their effectiveness, assists in advocating for the implementation of these programs. Broader implementation of effective programs could reduce the number of people experiencing poor mental health. 


\section{CONCLUSIONS}

The social-ecological model provides a framework that outlines the dynamic interplay of influences between people and their environments (McLaren \& Hawe, 2005). With a substantial proportion of the population likely to experience a mental or behavioral disorder at some point (Ferrari et al., 2013), the burden of these disorders needs to be addressed. Furthermore, the multiple and complex influences on mental health outcomes require a multi-level perspective that the social-ecological model offers.

At the individual level, people with mental illnesses experience various problems, including internalized stigma and comorbid chronic illnesses. Encouraging people with mental illnesses to be kind to themselves and develop the skill of self-compassion may reduce the negative outcomes that can result from internalized stigma. Innovative programs, such as Project UPLIFT, may reduce the impact of comorbidity by treating and preventing depression and anxiety among people with chronic illnesses (Thompson et al., 2014; Thompson et al., 2010).

At the relationship level, caregivers provide valuable support to people with mental and/or physical health conditions. However, these relationships are complex and at times are difficult for the caregiver. The spectrum of support that caregivers provide influences the burden they may experience, which can influence their quality of life and physical and mental health (Rees, O'Boyle, \& MacDonagh, 2001; Smerglia, Miller, Sotnak, \& Geiss, 2007). Aiding caregivers through support groups, respite care, and financial assistance may help reduce the burden they experience.

At the community level, barriers such as trust, community norms, needs of diverse populations, licensing laws, and access to emergency and safety services may contribute to the community burden of mental illnesses. Acknowledging community-level barriers and working with subpopulations, such as refugees, to understand how they view mental illnesses and mental health providers and to develop solutions to increase access to mental health services would ensure that interventions are tailored to their needs and community values.

Finally, at the societal level, influences on mental health include, among others, income equality, stigma and discrimination, and access to health care coverage. Each of these contributes to disparities among sub-populations, including those with poor mental health outcomes. Effective interventions addressing each of these factors have been developed, providing a foundation for reducing poor mental health outcomes at the societal level. Use of cost data to demonstrate their value could convince policy and decisionmakers to support wider dissemination and implementation.

Each of the levels described in this review offers opportunities for advocacy and intervention. Moving forward, advocacy and interventions that are designed to have an impact across the levels of the social-ecological model have the potential to contribute to progress in improving mental health outcomes. In Georgia, limited access to mental health services (Aron et al., 2009) and lower levels of funding for mental illnesses suggest that mental health advocacy at the various levels of the socialecological model could help address the burden of mental illnesses in this state (National Association of State Mental Health Program Directors Research Institute, Inc., 2006).

\section{References}

American Psychological Association (APA). (n.d.) What do family caregivers do? Retrieved from http://www.apa.org/pi/about/publications/caregivers/faq/family. aspx downloaded 5/9/2015

Ao, T., Taylor, E., Lankau, E., Sivilli, T., Blanton, C., Shetty, S., \& Lopes-Cardozo, B. (2012). An Investigation into Suicides among Bhutanese Refugees in the US 2009-2012: Stakeholders Report.

Aron, L., Honberg, R., Duckworth, K., et al. (2009). Grading the States 2009: A Report on America's Health Care System for Adults with Serious Mental Illness, Arlington, VA: National Alliance on Mental Illness.

Aschbrenner, K. A., Greenberg, J. S., Allen, S. M., \& Seltzer, M. M. (2010). Subjective burden and personal gains among older parents of adults with serious mental illness. Psychiatric Services, 61(6), 605-611.

American Telemedicine Association (ATA). (2013). Telemedicine and Telehealth services. Retrieved from www.americantelemed.org

Baicker, K., Taubman, S. L., Allen, H. L., Bernstein, M., Gruber, J. H., Newhouse, J. P., . . . Smith, J. (2013). The Oregon experiment--effects of Medicaid on clinical outcomes. New England Journal of Medicine, 368(18), 1713-1722

Beronio, K., Glied, S., \& Frank, R. (2014). How the Affordable Care Act and Mental Health Parity and Addiction Equity Act Greatly Expand Coverage of Behavioral Health Care. The Journal of Behavioral Services and Research, 41(4): 410-428.

Berube, A. \& Holmes, N. (2015). Report: Some cities are still more unequal than others - an update. The Brookings Institution. Retrieved May 21, 2015, from http://www.brookings.edu/research/reports2/2015/03/cityinequality-berube-holmes

Bostwick, W. B., Boyd, C. J., Hughes, T. L., West, B. T., \& McCabe, S. E. (2014). Discrimination and mental health among lesbian, gay, and bisexual adults in the United States. American Journal of Orthopsychiatry, 84(1), 35-45. doi: 10.1037/h0098851

Breslau, J., Miller, E., Jin, R., Sampson, N. A., Alonso, J., Andrade, L. H., ... Kessler, R. C. (2011). A multinational study of mental disorders, marriage, and divorce. Acta Psychiatrica Scandinavica, 124(6), 474-486.

Bryant, R. A. (2011). Psychological interventions for trauma exposure and PTSD. In A. Stein, M. J. Friedman, \& Blanco, C. (Eds.), Post-traumatic stress disorder (pp. 171-202). Oxford, United Kingdom: Wiley-Blackwell.

Bureau of Population, Refugees, and Migration (2015). Worldwide Refugee Admissions Processing System (WRAPS). Retrieved from http://www.wrapsnet.org

Burns, J. K., Tomita, A., \& Kapadia, A. S. (2014). Income inequality and schizophrenia: increased schizophrenia incidence in countries with high levels of income inequality. International Journal of Social Psychology, 60(2), 185-196.

Centers for Disease Control and Prevention. (2013). Stigma of mental illness. Retrieved from http://www.cdc.gov/mentalhealth/data_stats/mental-illness.htm

Chase, L. (2012). Promoting Psychosocial Resilience among Bhutanese Refugees in Nepal: A Study of Ethnopsychology, Coping Strategies, and Community Resources. [Fulbright Report] 
Clement, S., Schauman, O., Graham, T., Maggioni, F., EvansLacko, S., Bezborodovs, N., . . . Thornicroft, G. (2014). What is the impact of mental health-related stigma on help-seeking? A systematic review of quantitative and qualitative studies. Psychological Medicine, 1-17. doi: 10.1017/S0033291714000129

De Hert, M., Correll, C. U., Bobes, J., Cetkovich-Bakmas, M., Cohen, D., Asai, I.,...Leucht, S. (2011). Physical illness in patients with severe mental disorders. I. Prevalence, impact of medications and disparities in health care. World Psychiatry, 10(1), $52-77$.

Dellifraine, J. L. \& Dansky, K. J. Home-based telehealth: A review and meta analysis. Journal of Telemedicine and Telecare, 14(2), 62-66.

Drapalski, A. L., Lucksted, A., Perrin, P. B., Aakre, J. M., Brown, C. H., DeForge, B. R., \& Boyd, J. E. (2013). A model of internalized stigma and its effects on people with mental illness. Psychiatric Services, 64(3), 264-269.

Drew, N. (1991). Combating the social isolation of chronic mental illness. Journal of Psychosocial Nursing and Mental Health Services, 29(6), 14-17.

Evans-Lacko, S., Henderson, C., Thornicroft, G., McCrone, P. (2013). Economic evaluation of the anti-stigma social marketing campaign in England 2009-2011. British Journal of Psychiatry, 55, s95-101.

Ferrari, A. J., Charlson, F. J., Norman, R. E., Patten, S. B., Freedman, G., Murray, C. J., et al. (2013). Burden of depressive disorders by country, sex, age, and year: findings from the global burden of disease study 2010. PLoS Medicine, 10(11). doi: 10.1371/journal.pmed.1001547

Franks, M. M., Stephens, M. A. P., Rook, K. S., Franklin, B. A., Keteyian, S. J., \& Artinian, N. T. (2006). Spouses' provision of health-related support and control to patients participating in cardiac rehabilitation. Journal of Family Psychology, 20(2), 311-318.

Gallant, M. P., Spitze, G. D., \& Prohaska, T. R. (2007). Help or hindrance? How family and friends influence chronic illness self-management among older adults. Research on Aging, 29(5), 375-409.

Gehi, A., Haas, D., Pipkin, S., \& Whooley, M. A. (2005). Depression and medication adherence in outpatients with coronary heart disease. Archives of Internal Medicine, 165(21), 2508-2513.

Gorst-Unsworth, C., \& Goldenberg, E. (1998). Psychological sequelae of torture and organized violence suffered by refugees from Iraq: Trauma-related factors compared with social factors in exile. British Journal of Psychiatry, 172, 90-94.

Hatzenbuehler, M. L., Phelan, J. C., \& Link, B. G. (2013). Stigma as a Fundamental Cause of Population Health Inequalities. American Journal of Public Health, 103(5), 813-821. doi: 10.2105/AJPH.2012.301069

Heaney, C. A., \& Israel, B. A. (2008). Social networks and social support. In R. B. Glanz K, Lewis F (Ed.), Health behavior and health education: Theory, research, and practice (4th ed., pp. 189-210). San Francisco: Jossey-Bass.

Hofmann, S. G., Sawyer, A. T., Witt, A. A., \& Oh, D. (2010). The effect of mindfulness-based therapies on anxiety and depression: a meta-analytic review. Journal of Consulting and Clinical Psychology, 78(2), 169-183.

Jones, C., Hacker, D., Cormac, I., Meaden, A., \& Irving, C. B. (2012). Cognitive behavioural therapy versus other psychosocial treatments for schizophrenia. Cochrane Database Systematic Reviews, doi: 10.1002/14651858.CD008712.pub2.

Kessler, R. C., Aguilar-Gaxiola, S., Alonso, J., Chatterji, S., Lee, S., Ormel, J., Ustun, T. B., \& Wang, P. S. (2009). The global burden of mental disorders: An update from the WHO World Mental Health (WMH) surveys. Epidemiologia Psichiatria Sociale, 18(1), 23-33.
Kessler, R. C. Chiu, W. T., Demler, O., \& Walter, E. E. (2005). Prevalence, severity, and comorbidity of 12-month DSM-IV disorders in the National Comorbidity Survey Replication. Archives of General Psychiatry, 62, 617-709.

Kessler, R. C., Ormel, J., Demler, O., \& Stang, P. E. (2003). Comorbid mental disorders account for the role impairment of commonly occurring chronic physical disorders: Results from the National Comorbidity Survey. Journal of Occupational and Environmental Medicine, 45, 1257-1266.

Kroenke, K. (2003), Patients presenting with somatic complaints: epidemiology, psychiatric co-morbidity and management. Int. J. Methods Psychiatric Research, 12, 34-43. doi: 10.1002/mpr.140

Langheim, F.J.P., Shim, R.S., Druss, B.G. (2015). Poor Access to Health Care. In M.T. Compton \& R.S. Shim (Eds.), The Social Determinants of Mental Health (213-233).

Lefley, H. P. (2009). Family psychoeducation for serious mental illness. New York: Oxford University Press.

Lin, E. H. B., Katon, W., Von Korff, M., Rutter, C., Simon, G. E., Oliver, M.,...Young, B. (2004). Relationship of depression and diabetes self-care, medication adherence, and preventive care. Diabetes Care, 27, 2154-2160.

Martens, W. (2007). Prevalence of Depression in Various Ethnic Groups of Immigrants and Refugees: Suggestions for Prevention and Intervention. The International Journal of Mental Health Promotion, 9(1), 25-33. DOI: 10.1080/14623730.2007.9721831

McLaren, L. \& Hawe, P. (2005). Ecological Perspectives in Health Research. Journal of Epidemiology and Community Health, 59 , 6-14.

Miller, K., \& Rasco, L. (2004). The Mental Health of Refugees: Ecological Approaches to Healing and Adaptation. New York: Psychology Press.

Morris, M., Popper, S., Rodwell, T., Brodine, S., \& Brouwer, K. (2009). Healthcare Barriers of Refugees Post-resettlement. Journal of Community Health, 34(6), 529-538.

National Association of State Mental Health Program Directors Research Institute, Inc. (NRI Inc.). (2006). State Mental Health Agency Profiles Systems (Profiles) and Revenues Expenditures Study: Revenues and Expenditures Reports from 2006. National Association of State Mental Health Program Directors Research Institute, Inc. Retrieved from http://www.nriinc.org/projects/Profiles/Prior_RE.cfm

National Alliance for Caregiving, \& AARP. (2009). Caregiving in the US. Washington, D.C.: National Alliance for Caregiving, AARP, MetLife Foundation.

Neff, K. (2003). The Development and Validation of a Scale to Measure Self-Compassion. Self and Identity, 2, 223-250.

Neff, K. D., Rude, S. S. \& Kirkpatrick, K. L. (2007). An examination of self-compassion in relation to positive psychological functioning and personality traits. Journal of Research in Personality, 41, 908-916.

Nieboer, A. P., Schulz, R., Matthews, K. A., Scheier, M. F., Ormel, J., \& Lindenberg, S. M. (1998). Spousal caregivers' activity restriction and depression: a model for changes over time. Social Science \& Medicine, 47(9), 1361-1371.

Office of the Surgeon General, Center for Mental Health Services, \& National Institute of Mental Health (NIMH). (2001). Mental Health: Culture, Race, and Ethnicity: A Supplement to Mental Health: A Report of the Surgeon General. Rockville (MD): Substance Abuse and Mental Health Services Administration; Chapter 1. Introduction. Available from: http://www.ncbi.nlm.nih.gov/books/NBK44246/

Pabayo, R., Kawachi, I., \& Gilman, S. E. (2014). Income inequality among American states and the incidence of major depression. Journal of Epidemiology and Community Health, 68(2), 110-115. doi: 10.1136/jech-2013-203093

Pernice, R., \& Brook, J. (1996). Refugees' and immigrants' mental health: Association of demographic and post-migration factors. Journal of Social Psychology, 136, 511-519. 
Pickett, K. E., \& Wilkinson, R. G. (2015). Income inequality and health: a causal review. Social Science and Medicine, 128, 316326. doi: 10.1016/j.socscimed.2014.12.031

Pinquart, M., \& Sorensen, S. (2003). Differences between caregivers and noncaregivers in psychological health and physical health: a meta-analysis. Psychology \& Aging, 18(2), 250-267.

Ramsay, C., Walker, E. R., Ramsay, R., Compton, M. T., Thompson, N. J. (2010). An exploration of perceptions of possible depression prevention services for caregivers of elderly or chronically ill adults in rural Georgia. Community Mental Health Journal, 48(20), 167-178.

Representation of Services, Georgia administrative rule 510-5-.07 (2004).

Rojas, S. V. \& Gagnon, M-P. (2008). A systematic review of the key indicators for assessing telehomecare cost-effectiveness. Telemedicine and e-Health, 14(9) 896-904.

Rosland, A. M., Heisler, M., \& Piette, J. D. (2012). The impact of family behaviors and communication patterns on chronic illness outcomes: a systematic review. Journal of Behavioral Medicine, $35(2), 221-239$.

Sales, E. (2003). Family burden and quality of life. Quality of life research, 12(1), 33-41.

Sanden, V. D. R., Stutterheim, S. E., Pryor, J. B., Kok, G., \& Bos, A. E. R. (2014). Coping with stigma by association and family burden among family members of people with mental illness. Journal of Nervous and Mental Disease, 202(10), 1-9.

Sbarra, D. A., Smith, H. L., \& Mehl, M. R. (2012). When leaving your ex, love yourself: Observational ratings of self-compassion predict the course of emotional recovery following marital separation. Psychological Science, 23, 261-269.Thompson, N. J. (2014). Project UPLIFT CF: A Program to Self-Manage Anxiety and Depression for People with Cystic Fibrosis. Report to the Center for Outcomes Research and Public Health.

Shapiro, S. L., Brown, K. W., \& Biegel, G. M. (2007). Teaching self-care to caregivers: Effects of mindfulness-based stress reduction on the mental health of therapists in training. Training and Education in Professional Psychology, 1(2), 105-115.

Soto, J. A., Dawson-Andoh, N. A., \& BeLue, R. (2011). The relationship between perceived discrimination and Generalized Anxiety Disorder among African Americans, Afro Caribbeans, and non-Hispanic Whites. Journal of Anxiety Disorders, 25(2), 258-265. doi: 10.1016/j.janxdis.2010.09.011

Thompson, N.J., Patel, A.H., Selwa, L.M., Stoll, S.C., Begley, C.E., Johnson, E.K. \& Fraser, R.T. (2014). The Efficacy of Project UPLIFT for Prevention: Distance Delivery of
Mindfulness-based Depression Prevention. Journal of Consulting and Clinical Psychology. doi:10.1037/a0038404

Thompson, N.J., Walker, E.R., Obolensky, N., Winning, A., Barmon, C., Dilorio, C. \& Compton, M.T. (2010). Distance delivery of mindfulness-based cognitive therapy for depression: project UPLIFT. Epilepsy and Behavior, 19(3), 247-254.

Thornicroft, G., Rose, D., \& Kassam, A. (2007). Discrimination in health care against people with mental illness. International Review of Psychiatry, 19(2), 113-122. doi: 10.1080/09540260701278937

U.S. Census Bureau. (2014). Historical Income Tables: Households. Table H-3. Mean Household Income Received by Each Fifth and Top 5 Percent. Retrieved May 21, 2015, from https://www.census.gov/hhes/www/income/data/historical/house $\underline{\text { hold } /}$

U.S. Department of Health \& Human Services. (2014). Healthy People 2020. Retrieved May 21, 2015, from https://www.healthypeople.gov/sites/default/files/HP2020_broch ure_with_LHI_508_FNL.pdf

U.S. Department of Health \& Human Services. (2013). Healthy People 2020: Social Determinants of Health. Retrieved May 21, 2015, from https://www.healthypeople.gov/2020/topicsobjectives/topic/social-determinants-health

U.S. Public Health Service. (2000). Report of the Surgeon General's Conference on Children's Mental Health: A National Action Agenda. Washington, DC: Department of Health and Human Services.

Vinokur, A. D., Vanryn, M., Gramlich, E. M., \& Price, R. H. (1991). Long-term follow-up and benefit-cost-analysis of the JOBS program: A preventive intervention for the unemployed. Journal of Applied Psychology, 76(2), 213.

Waghorn, G., \& Lloyd, C. (2005). The employment of people with a mental illness. Australian e-Journal for the Advancement of Mental Health, 4(2), 129-171.

Walker, E. R., Barmon, C., McGee, R. E., Engelhard, G., Sterk, C. E., Dilorio, C., Thompson, N. J. (2014). Perspectives of adults with epilepsy and their support persons on self-management support. Qualitative Health Research, 24(11), 1553-66.

West, M. L., Yanos, P. T., Smith, S. M., Roe, D., \& Lysaker, P. H. (2011). Prevalence of internalized stigma among persons with severe mental illness. Stigma Research and Action, 1(1), -10.

Witt, W.P., Keller, A., Cottlieb, C., Litzelman, K., Hampton, J., Maguire, J., et al. (2011). Access to adequate outpatient depression care for mothers in the U.S.: A nationally representative population-based study. The Journal of Behavioral Health Services Research, 38(2): 191-204. 